\title{
Análise de uma planta de potência híbrida heliotérmica-biomassa
}

\author{
Thales Soler Ferrari, Joaquim Eugênio Abel Seabra.
}

\section{Resumo}

A maior utilização de fontes renováveis de energia bem como seu uso mais eficiente se fazem necessários tendo em vista a necessidade brasileira e mundial de redução do consumo de combustíveis fosseis. Este trabalho envolveu uma análise do desempenho potencial de uma planta de potência híbrida helitérmica-biomassa, considerando a implantação em duas localidades distintas no Brasil: Bom Jesus da Lapa (BA) e Campo Grande (MS).

\section{Palavras-chave:}

Fontes renováveis, Geração de potência, Termodinâmica.

\section{Introdução}

O projeto apresenta a análise da implantação de uma planta de potência híbrida, que utiliza como fonte de calor concentradores solares de coletores parabólicos (CSP) e a combustão de biomassa sólida, a fim de complementar a geração. A planta (Figura 1) é composta pelo coletor solar, pela caldeira e seus componentes, e da parte de potência. O estudo pode ser dividido em três etapas: a avaliação do potencial solar e disponibilidade de biomassa no território brasileiro e definição das localidades; construção do modelo de simulação da planta de potência alimentada pelo sistema híbrido; e a quantificação do consumo de biomassa complementar, responsável por garantir a geração de eletricidade constante.

\section{Resultados e Discussão}

A definição das localidades foi feita com base no estudo da disponibilidade solar (irradiação DNI - Direct Normal Irradiation) e da oferta de biomassa. Por meio do software System Advisor Model (SAM) e com base no critério solar, foram escolhidas as regiões de Bom Jesus da Lapa (BA) e Campo Grande (MS), aqui referidas como casos 1 e 2. Os combustíveis complementares são, respectivamente, a lenha e o bagaço de cana.

A simulação da planta de potência foi realizada com auxílio do software Engineering Equation Solver (EES), por meio da modelagem de cada um dos componentes do sistema [2] como um volume de controle operando em regime permanente.

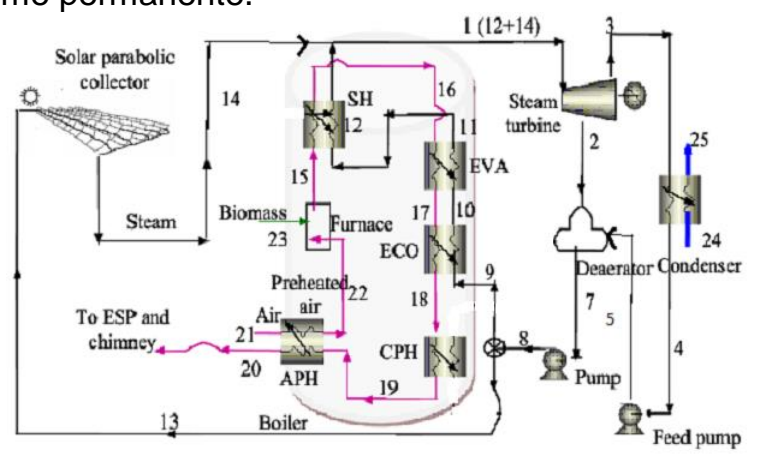

Figura 1. Representação esquemática do sistema estudado. Fonte: SRINIVAS e REDDY (2014)

A primeira etapa da simulação consistiu na análise dos extremos: utilizando unicamente os coletores solares, a fim de encontrar a máxima potência gerada; e os respectivos consumos de biomassa necessários para manter tal geração, quando utilizando unicamente a caldeira. Os resultados são apresentados na Tabela 1.

Tabela 1. Resultados da simulação dos extremos

\begin{tabular}{|c|c|c|c|}
\hline Caso & $\begin{array}{c}\text { Input de Calor } \\
\text { Solar [MW] }\end{array}$ & $\begin{array}{c}\text { Potência } \\
\text { Líquida [MW] }\end{array}$ & $\begin{array}{c}\text { Consumo de } \\
\text { biomassa [kg/s] }\end{array}$ \\
\hline 1 & 128,268 & 36,017 & 18,73 \\
\hline 2 & 131,942 & 37,048 & 20,57 \\
\hline
\end{tabular}

A evolução do comportamento ao longo do ano e do dia é ilustrada na Figura 2.

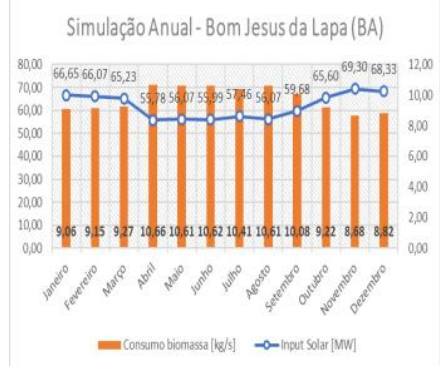

(a)

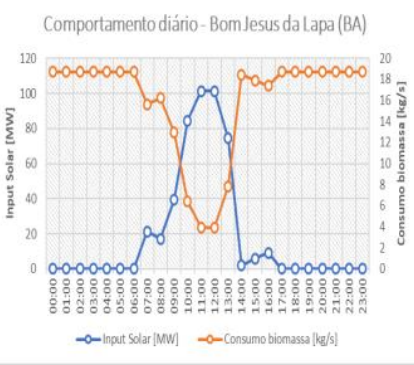

(b)
Figura 2. Comportamento do input solar e do consumo de biomassa ao longo do ano (a) e do dia (b) para o Caso 1.

\section{Conclusões}

Plantas de potência CSP híbridas têm potencial para serem utilizadas na geração de energia elétrica no território brasileiro, sobretudo nas regiões analisadas, uma vez que possuem a disponibilidade solar e potencial de produção de biomassa. Foram obtidos valores aceitáveis de eficiência, de maneira que esta aumenta com a participação solar. O desenvolvimento de novas tecnologias e do aperfeiçoamento das que já estão disponíveis do mercado terão papel essencial para a redução de custos e aumento da competitividade desta fonte de geração de energia, a fim de diminuir a dependência de combustíveis fosseis, e aumentar a diversificação da matriz energética brasileira.

\section{Agradecimentos}

Agradeço ao PIBIC (SAE) e ao CNPq pelo apoio financeiro concedido.

\footnotetext{
${ }^{1}$ PENAFIEL, R. A. S. Cenários de Geração de Eletricidade a partir de GeradoresHeliotérmicos no Brasil: A Influência do Armazenamento de Calor e da Hibridização. Mestrado - Rio de Janeiro: UFRJ/COPPE, 2011.

2 SRINIVAS, T.; REDDY, B. V. Hybrid solar-biomass power plant without energy storage.Case Studies in Thermal Engineering, v. 2, p. $75-81$, mar. 2014 .
} 